\title{
Human Genome Organisation
}

National Cancer Institute

\section{Source}

National Cancer Institute. Human Genome Organisation. NCI Thesaurus. Code C48690.

An international org anization of scientists involved in human genetics. Established in 1989 by a collection of the world's leading human geneticists, the primary ethos of the Human Genome Organisation is to promote and sustain international collaboration in the field of human genetics. 